\title{
JURISPRUDENCIA LABORAL
}

\author{
A cargo de: FERNANDO MALESPÍN MARTÍNEZ \\ Profesor Adjunto de Derecho Laboral \\ Universidad Centroamericana
}

\section{LA PRESCRIPCIÓN, LA APELACIÓN Y LA CONVENCIÓN COLECTIVA}

\begin{abstract}
$\Upsilon$ ienen ante ustedes tres sentencias de la Sala de lo Laboral del Tribunal de 1 Apelaciones de Managua que abordan tres columnas del Derecho Laboral: la prescripción, la apelación y la convención colectiva.

Cada sentencia contiene consideraciones importantes a tener en cuenta para el correcto ejercicio del Derecho Laboral.
\end{abstract}

\section{SENTENCIA No $173 / 2003$}

\author{
JOSÉ ANTONIO ARIAS GARCÍA \\ VS. \\ JUNTA LIQUIDADORA DEL BANCO DEL CAFÉ
}

TRIBUNAL DE APELACIONES. CIRCUNSCRIPCIÓN MANAGUA, SALA DE LO LABORAL. Managua, treinta de septiembre del dos mil tres. Las nueve y treinta minutos de la mañana.

\section{VISTOS - RESULTA}

Por escrito presentado a las cinco de la tarde del veinticinco de mayo del dos mil uno, ante el Juzgado Segundo de Distrito del Trabajo de Managua, el Licenciado Luis Alberto Urbina Beltrand, en calidad de Apoderado Especial Judicial del Señor JOSÉ ANTONIO ARIASGARCIA, mayorde edad, casado, economistay de estedomicilio, para que por sentencia firme se le obligue a pagar a la JUNTA LIQUIDADORA DEL BANCO DEL CAFÉ, la cantidad de Ochenta mil sesenta y tres dólares, en concepto de complemento de indemnización por cargo de confianza, prestaciones sociales de Enero a Octubre del dos mil y gastos de representación. Expresó el Apoderado Especial Judicial de la parte actora que su mandante inició a laborar el 
dieciocho de septiembre de mil novecientos noventa y cinco, desempeñándose como Gerente General, devengando un salario de seis mil dólares, que eran entregados en córdobas y en dólares, siendo despedido, liquidándosele solamente la parte pagada en córdobas. Se dieron los estamentos procesales; en la contestación de la demanda compareció el doctor Pedro Reyes Vallejos, en calidad de Apoderado General Judicial de la Junta Liquidadora Banco del Café, quien negó, rechazó y contradijo los puntos de la misma e invocó prescripción del reclamo laboral, mandándose a oír a la parte contraria. Se abrió a pruebas el juicio por el término de ley, ambas partes aportaron lo que estimaron a bien. Por sentencia de las once de la mañana del veintinueve de enero del dos mil uno, la señora Juez dirimió la contienda, sin lugar a la excepción opuesta por la parte demandada y con lugar al pago de complemento de indemnización por cargo de confianza, vacaciones y décimo tercer mes, sin lugar a los otros reclamos por el actor, sin costas. No conforme la demandada, apeló de la misma, llegadas las diligencias originales a conocimiento de este Tribunal, ambas partes se apersonaron y siendo el caso de resolver,

\section{SE CONSIDERA}

IEl Arto. 350 C.T., obliga a esta Sala a revisar el proceso en los puntos de la resolución que causen agravio a las partes. INTERRUPCIÓN DE LA PRESCRIPCIÓN. PLAZO PARA LA INTERPOSICIÓN DE LA DEMANDA: EL ARTO. 257 C.T., ESTABLECE QUE: “Las acciones que se deriven del presente Código, de la Convención Colectiva y del Contrato individual de trabajo prescribirán en un año, con las excepciones que se establecen en los artículos siguientes: ..." Lo anterior quiere decir, que salvo las excepciones que se establecen en los artículos siguientes (Artos. 258, 259 y 260 C.T.), la regla general establecida en el Arto. 257 C.T., es que derivada una acción de una de las fuentes ahí señaladas el plazo para acudir al Juez competente a interponer la correspondiente demanda es de un año. MEDIOS DE PRUEBA: "Los medios de prueba, son aquellos elementos de naturaleza estrictamente procesal, cuya función es introducir en el proceso los datos de la realidad que apoyen las alegaciones de las partes, - en cuanto éstas consistan en afirmaciones de hecho - y contribuyan a formar la convicción del juzgador sobre la veracidad o falsedad de éstas. .." En el caso de autos el medio de prueba propuesto no se trata de un medio personal, es decir que la fuente de la prueba es una persona, sino que se trata de la categoría de los medios de prueba reales, que son aquellos en que la fuente de la prueba es una cosa. Recapitulando: Tenemos que en un determinado momento surge un derecho a entablar una acción en la vía judicial para que sometida su pretensión a las decisiones de los Tribunales de Justicia obtener el cumplimiento de esa pretensión. Entre el 
momento en que surge ese derecho de acudir a los Tribunales y el momento en que efectivamente se acude al Juez competente a interponer la correspondiente demanda, no debe transcurrir más de un año, so pena de que ese derecho prescriba, es decir se pierda. CASO DE AUTOS: En el caso de autos, habiendo transcurrido más del año, el actor por un medio de prueba consistente en una cosa, pretende probar que interrumpió el plazo de un año establecido en la ley para la prescripción. En este caso, ese medio de prueba que debe llevar a la convicción del Juez son documentos, de los que el Juez debe analizar su pertinencia y sobre todo su valor y autenticidad. En relación a estos medios de prueba, tenemos que fueron generados por el propio actor quien los suscribe y no por la parte demandada. En su escrito de expresión de agravios dicha parte demandada y aquí apelante enfáticamente dijo: “. . . Dichos documentos, ...” “. . . no aparecen con el sello oficial de correspondencia recibida de la institución, y la única señal que tienen es un recibido o una firma que no se identifica. .." “... Es aceptable que una gestión de cobro extrajudicial interrumpa la prescripción, pero cuando llena requisitos que la hacen inobjetable a la simple lógica y al análisis, sobre todo si se trata de hacerla efectiva ante un banco, donde hay control de correspondencia, sello de recibido y fecha de recibido. De tales requisitos, que no cumplen los atestados de los folios 69 al 71 del cuaderno de primera instancia, debe cerciorarse el interesado para poder hacer valer sus derechos en el caso que nos ocupa. " La Juez A-quo sin profundizar ni constatar los requisitos esenciales para la validez de un documento y de un documento de gestión de cobro, rechazó equivocadamente la prescripción alegada en nombre de mi mandante en tiempo y forma y que mata todo reclamo, independientemente de que en el presente caso el demandante no tiene fundamento legal en su pretensión..."

\section{CONCLUSIÓN}

De lo anterior, resulta que el documento que está supuesto a sostener todo el andamiaje del proceso, y que fue fuertemente cuestionado, no emana de la parte demandada, sino que fue concebido, elaborado y suscrito por la propia parte actora, quien además fue la que lo presentó. Adicionalmente, no ha sido reconocido como válido por la parte demandada, ni fue sometido a verificación alguna, más bien esta parte demandada comparece a hacer observaciones pertinentes a cuestionar fuertemente dichos documentos, quien evidencia que hay una rúbrica de recibido de la que no se acreditó judicialmente a quién pertenece, y adicionalmente no hay ni siquiera un solo sello de recibido de ninguna oficina de la institución bancaria. En vista de lo anterior, siendo cierto que el plazo de la prescripción transcurrió sobradamente, no cabe más que dar lugar a la apelación intentada y declarar la 
prescripción de la acción intentada por el actor. En consecuencia, se debe REVOCAR la sentencia recurrida.

\title{
POR TANTO
}

En vista de lo expuesto, disposiciones legales citadas y con apoyo en los Artos. 271, 272 y 347 C.T., los Suscritos Magistrados,

\section{RESUELVEN}

I.- Ha lugar a la apelación intentada y se declara prescrita la acción intentada por la parte actora. En consecuencia, se REVOCA la sentencia recurrida. II.- No hay costas. El Magistrado DOCTOR HUMBERTO SOLÍS BARKER, disiente del voto de mayoría y vota porque se confirme la sentencia apelada, por la razón de que, en lo que se refiere al inicio del término de prescripción, EN LO LABORAL, su opinión es que debe contarse desde que termina la relación laboral, ya que hacer prescribir un derecho del trabajador mientras está vigente esa relación, es decir en esa situación de dependencia, equivale por lo general, conforme lo demuestra la experiencia, a ponerlo a escoger entre efectuar el reclamo de sus derechos o conservar su empleo. Sus razones son las mismas ya dadas en sentencia número 118 en contra de la misma demandada, de las tres y treinta minutos de la tarde del veintitrés de julio del dos mil tres. Cópiese. Notifíquese. Con testimonio concertado de lo resuelto, vuelvan los autos de primera instancia al Juzgado de origen. HUMBERTO SOLIS BARKER.---A. GARCÍA GARCÍA.---R. BÁRCENAS M.----- IVANIA LÓPEZ. SRIA. Es conforme con su original. Managua, uno de octubre del dos mil tres.

\section{SENTENCIA N $\mathbf{N}^{\mathrm{o}} \quad 174 / 2003$}

\author{
JORGE ALBERTO ORTEGA RAMÍREZ VS. \\ INSTITUTO DE DESARROLLO RURAL ( IDR )
}

TRIBUNAL DE APELACIONES. CIRCUNSCRIPCIÓN MANAGUA, SALA DE LO LABORAL. Managua, treinta de septiembre del dos mil tres. Las nueve y treinta y cinco minutos de la mañana. 


\section{VISTOS - RESULTA}

Por escrito de las dos y veinticinco minutos de la tarde del catorce de marzo del dos mil dos, se presentó ante la señora Juez Segundo de Distrito del Trabajo de Managua, el doctor JORGE ALBERTO ORTEGA RAMÍREZ, mayor de edad, casado, abogado y notario y de este domicilio a interponer demanda con acción de pago de indemnización de conformidad con el Arto. 47 C.T., en contra del INSTITUTO DE DESARROLLO RURAL IDR. Expone el recurrente que inició a laborar el dieciséis de junio de mil novecientos noventa y ocho, desempeñándose como Asesor Legal de la Institución. Se dieron los estamentos legales. Se presentó el Licenciado José Ramiro Sánchez López, en calidad de Apoderado General Judicial de la parte demandada a quien se le dió intervención y contestó la demanda negando, rechazando y contradiciendo cada uno de los puntos de la misma, oponiendo las excepciones de oscuridad de la demanda y falta de acción, de éstas se mandó a oír a la parte contraria. Se abrió a pruebas el juicio por el término de ley, ambas partes aportaron lo que estimaron a bien. Por sentencia de las ocho y treinta minutos de la mañana del tres de julio del dos mil dos, la señora Juez Segundo de Distrito del Trabajo de Managua resolvió con lugar la excepción de falta de acción opuesta por la demandada, sin costas. No conforme la parte actora apeló de la misma, y llegadas las diligencias originales a conocimiento de este Tribunal, ambas apartes se apersonaron y siendo el caso de resolver,

\section{SE CONSIDERA}

I.- El Arto. 350 C.T., obliga a esta Sala a revisar el proceso en los puntos de la resolución que causen agravio a las partes. A. ANTECEDENTES NECESARIOS: En caso de autos, el actor apeló de la sentencia de término de la Juez A-quo. La Juez A-quo admitió la apelación interpuesta y emplazó debidamente a las partes para que dentro del término de ley concurrieran ante este Tribunal a hacer uso de sus derechos. La parte actora, en tiempo concurrió ante este Tribunal y presentó escrito solicitando se le tuviera por personado, luego presentó otro escrito en el cual reiteró su pedimento de tenerle por personado diciendo en la parte pertinente al pedimento: “. . Estoy en tiempo para personarme, como así lo estoy haciendo y os pido nuevamente que me deis la intervención de ley.” En el ínterin entre ambos escritos compareció la parte apelada. Esta Sala tuvo por personadas, tanto a la parte actora como a la parte apelada y les dio intervención de ley. Haciendo uso de su derecho, la parte apelada refiriéndose al actor, aquí apelante, en la parte pertinente de su escrito manifestó: “. . . quien no expresó agravios y al no haberlos, no hay justificación de la apelación, por lo cual pido 
que se declare sin lugar la apelación. .." Posteriormente el actor aquí apelante, expresó sus agravios. B.- DE LA SITUACIÓN JURÍDICA DEL RECURSO DE APELACIÓN DE LA PARTE ACTORA. Sentado el punto anterior previo a entrar o no a conocer el fondo del asunto, es necesario primero analizar desde el punto de vista jurídico cuál es la situación del recurso de apelación interpuesto y así tenemos: El asunto a debatir es el efecto enervatorio, o no, del lapso de tiempo o retraso transcurrido entre el apersonamiento y la expresión de agravios. Sabemos que los recursos pueden estar sometidos a determinados requisitos o condiciones, la falta o incumplimiento de los cuales pueden constituir causas obstativas que conducen a la inadmisión del recurso. Del examen del trámite en estudio vemos que en el caso de autos la parte actora apeló de la sentencia de la Juez A-quo. El trámite establecido por el legislador laboral para estos casos es el siguiente: a ambas partes se les emplaza " para que dentro de los tres días de notificada la admisión, comparezcan a estar a derecho y a expresar agravios ante la autoridad correspondiente de segunda instancia...” (Arto. 353 C.T.). Cuando alguna de las partes no ejercita oportunamente y en la forma legal alguna facultad o algún derecho procesal, o incumple alguna obligación de la misma naturaleza, se produce una situación procesal que se denomina preclusión. Según Pallares la preclusión es una figura que surge debido a que el proceso está constituido por diversas secciones o períodos, dedicados cada uno de ellos al desenvolvimiento de determinadas actividades. Concluido este período se pasa al siguiente y así sucesivamente y no es posible estar retrocediendo a períodos anteriores. En resumen si no se produce el acto procesal adecuado en el término que fije la ley, las actuaciones posteriores no tienen el efecto de revivir el plazo. Siguiendo con el caso de estudio de los requisitos y condiciones de la apelación, tenemos que una vez emplazadas las partes para que dentro de los tres días de notificados la admisión comparezcan a esta Sala a personarse y a expresar sus respectivos agravios dentro del término de ley, concluido este período ya no es posible retrocederlo (artículos 174 y $176 \mathrm{Pr}$ ) y lo que cabe es pasar al siguiente período que es la fase de contestación de los respectivos agravios. Distinto sería el caso si la contraparte no hace valer la preclusión y procede a contestar los agravios extemporáneos, pero en el caso de autos no es así, sino que la contraparte señaló expresamente que en su oportunidad los agravios no fueron expresados.

\section{CONCLUSIÓN}

Si bien es cierto que el apelante expresó agravios en escrito posterior, esto fue fuera del término que le había concedido la ley y con posterioridad a la solicitud de sanción del apelado, por lo que no tiene la virtud de subsanar la omisión. 
Consecuentemente por lo que hace a la apelación del actor aquí apelante no queda más que confirmar la sentencia apelada por falta de agravios.

\section{POR TANTO}

En vista de lo expuesto, disposiciones legales citadas y con apoyo en los Artos. 271, 272 y 347 C.T., los suscritos Magistrados,

\section{RESUELVEN}

I.- No ha lugar a la apelación intentada por la parte actora por falta en tiempo oportuno de agravios que revisar. En consecuencia se confirma la sentencia recurrida. II.- No hay costas. Cópiese. Notifíquese. Con testimonio concertado de lo resuelto, vuelvan los autos de primera instancia al Juzgado de origen. HUMBERTO SOLÍS BARKER.---- A. GARCÍA GARCÍA.----R. BÁRCENAS M.---- IVANIA LÓPEZ SRIA. Es conforme con su original. Managua, uno de octubre del dos mil tres.

\section{SENTENCIA $\mathbf{N}^{\circ} 179 / 2002$}

\section{EINAR JOSÉ ARÁUZ E. Y OTROS VS. ENITEL}

\section{TRIBUNAL DE APELACIONES. CIRCUNSCRIPCIÓN MANAGUA.} SALA DE LO LABORAL. Managua, diez de octubre del dos mil tres. Las doce y cinco minutos de la tarde.

\section{VISTOS - RESULTA}

Por escrito de las dos y treinta y cinco minutos de la tarde del doce de Julio del dos mil dos, se presentó ante el Juzgado Primero de Distrito del Trabajo de Managua, el señor EINAR JOSÉ ARÁUZ ECHEGOYEN, mayor de edad, soltero, Ingeniero en Sistemas y de este domicilio, a interponer demanda con acción de reintegro, en contra de la EMPRESA NICARAGÜENSE DE TELECOMUNICACIONES (ENITEL). Expresó el compareciente que inició a laborar para dicha empresa el uno de febrero del dos mil uno, desempeñándose como Administrador de Sistemas Operativos, devengando un salario de ocho mil seiscientos setenta y nueve córdobas mensuales. Se dieron los estamentos 
procesales. Se tuvo como Apoderada General Judicial de la empresa demandada a la Licenciada Karla Ninoska Pineda Gadea, quien negó, rechazó, impugnó y contradijo la demanda y opuso excepciones de falta de acción y de pago, de las que se mandó a oír a la parte contraria. Se le dio intervención de ley al Licenciado Eugenio José Membreño, en calidad de Apoderado Verbal Laboral del actor. Se abrió a pruebas el juicio donde ambas partes aportaron lo que estimaron a bien. En el interin del proceso el apoderado de la parte actora solicitó acumulación de autos, de los juicios promovidos por los señores Maira Adilia Echegoyen Toruño, Yessyka Patricia Guevara Muñoz y Wuelber de Jesús Castillo Ortiz, petición que la juez accedió. Por sentencia de las dos de la tarde del diecinueve de agosto del dos mil dos, la señora Juez dirimió la contienda declarando con lugar las excepciones opuesta por la demandada, sin lugar la demanda de reintegro y sin costas. No conforme la parte actora, apeló de la misma, llegadas las diligencias originales a conocimiento de este Tribunal, ambas partes se apersonaron, y siendo el caso de resolver;

\section{SE CONSIDERA}

I.- $\mathrm{Al}$ tenor del Arto. 350 C.T., procede la Sala a revisar los puntos de agravios que le ocasiona a EUGENIO JOSE MEMBREÑO en su carácter de Apoderado Verbal Laboral de EINAR ARAUZ ECHEGONEN, MAIRA ADILIA ECHEGOYEN MARTINEZ, JESSYKA PATRICIA GUEVARA MUÑOZ y WUELBER CASTILLO ORTIZ la sentencia Nùmero 157 dictada por la Juez Primero de Distrito del Trabajo de esta ciudad de Managua a las dos de la tarde del día diecinueve de Agosto del año pasado, en que desestimó la pretensión de reintegro que demandaron a la EMPRESA NICARAGÜENSE DE TELECOMUNICACIONES Y CORREOS SOCIEDAD ANÓNIMA (ENITEL). Manifiesta que la Señora Juez A-quo no consideró el carácter de represalia que revisten los despidos al no conformarse la Comisión Bipartita conforme cláusula 21 del Convenio Colectivo vigente que se expande a toda clase de despido. Porque no se pronunció sobre las pruebas indubitables presentadas como son las leyes 293 publicada en la Gaceta, Diario Oficial el dos de Julio de mil novecientos noventa y ocho, Ley de Reformas a la Ley 210, Ley de Incorporación de Particulares en la Operación y ampliación de los Servicios Públicos de Telecomunicaciones. Ley que en sus Artos. 36 y 48 conceptúan el alcance de las concesiones, su exclusividad por un período de tres años que se corresponde por igual período con la estabilidad laboral, esta Ley 293 està incorporada al Convenio Colectivo vigente en su cláusula número 22 y consecuentemente forma parte de la contratación individual. Que también fue 
omitida como prueba indubitable la Ley número 436, "Ley de Interpretación Autèntica de los Artículos 47, 48 y 49 de la Ley Nro. 293, Ley de Reforma a la Ley Nro. 210, Ley de Incorporación de Particulares en la Operación y Ampliación de los Servicios Públicos de Telecomunicaciones. Que en tal sentencia privó el interés particular más que el interés pùblico. Y al no acogerse el reintegro cabía ordenar pagar los salarios dejados de percibir por el periodo de exclusividad que es igual al de su estabilidad conforme las leyes precitadas y citando expresamente la Ley 436 Arto. 49, inc. 2). Concluyendo que estando establecida la fundamentación del despido en Arto. 45 C.T., que el Convenio Colectivo les cubre y la Empresa no conformó la Comisión Bipartita, ella la Empresa violentó el procedimiento laboral, más la interpretación autèntica dada a la Ley 293 todo ello viene a dar por resultado la legitimidad de sus reclamaciones. II.- La parte recurrida alegó al contestar que las apreciaciones de la A-quo eran correctas, ajustadas a derecho. Que la cláusula 21 de la Convención Colectiva sòlo se aplica cuando al trabajador se pretende despedir con causa justa y así se desprende del literal d) de la referida cláusula que remite al Arto. 48 C.T., que es para despidos causados y el Arto. 45 C.T., es para los incausados. Que en primera instancia no se demostró lo demandado en base a Arto. 46 C.T., Ley 210 y sus reformas. Y la A-quo aplicó correctamente las disposiciones legales laborales y rechazó tal pretensión porque no se dieron los aludidos presupuestos del Arto. 46 C.T., y por eso dió lugar a la excepción de falta de acción interpuesta por ella. Que la Ley Nùmero 293, en su Arto. 48 no se contradice con las dos formas de despido a que remite el Código del Trabajo en sus Artos. 45 y 48 y por eso se hizo uso del Arto. 45 C.T., en los casos de autos. En cuanto a la Ley 436 referida varias veces con anterioridad fue publicada posteriormente a los despidos de los cuatros señores demandantes por lo que de ninguna manera sería aplicable en los casos de autos en virtud de la no retroactividad de la ley. Que las prestaciones de los cuatro demandantes ya fueron satisfechas y retiradas, que las otras pretensiones carecen de fundamento legal y por eso acogió la Señora Juez A-quo la excepción de pago. No cabía aplicar el Principio de Ultrapetitividad y que todo lo actuado ha sido tramitado conforme a derecho y las pretensiones y los agravios por parte de los recurrentes no tienen razón legal y solicitaba se confirmara la sentencia. III.- Analizando los cuatro libelos de demanda de las partes a quienes representa el Licenciado Membreño, vemos que cada una de ellas narran los hechos de sus despidos incausados fundamentados en Arto. 45 C.T., que por necesidades económicas retiraron liquidación, aunque inconformes y que éstas no anulan sus derechos. Al fundamentar su pretensión de reintegro por tal despido lo hacen señalando el Arto. 46 C.T., y la Ley Número 293 y sus reformas con respecto a la privatización de ENITEL. La parte demandada, negó, impugnó 
y contradijo la demanda, aduciendo que no pudo violentar la Ley Número 293 porque no tiene reformas y la estabilidad laboral no está en contra de lo que dispone el Arto. 45 C.T., y opone excepción de falta de acción y de pago. En la estación probatoria y antes se adjuntaron documentales por ambas partes: Tratándose de leyes como la número 210, "Ley de Incorporaciones de Particulares en la Operación y Ampliación de los Servicios Públicos de Telecomunicaciones; y Ley número 293, reformatoria de la anterior. La Convención Colectiva suscrita entre la Empresa ENITEL y sus trabajadores fechada el veinticuatro de Mayo del año dos mil dos, transcribiendo sus cláusula 21 y 22; hoja de liquidaciones; Constancia de que el Proyecto de "Ley de Interpretación auténtica de Artos. 47, 48 y 49 de la Ley No. 293 Ley de Reforma a la Ley No. 210 se encuentra pendiente de sanción al veinticinco de Julio del año pasado, recortes de periódicos acerca de dicha interpretación "Nuevo Diario, 17 de Julio del año dos mil dos. Dictámenes al respecto de tal interpretación y publicaciones laborales con sentencias de esta Sala insertas por el Doctor Pastor Torres Gurdián. Del análisis de la demanda y la prueba vemos que la discusión se hace en torno a la estabilidad laboral de los empleados de ENITEL. No obstante la A-quo estimó que por las liquidaciones que detalla en Considerando Hechos Probados 1 a 4; que retiraron los actores, ellos dieron por terminada la relación laboral y por ende no cabe el reintegro. No obstante, el reintegro no equivale a pago de prestaciones, ambos conceptos se manejan en artículos diferentes del Código del Trabajo, el Arto. 45 C.T., habla de despido incausado y su correspondiente indemnización viniendo a ser el Arto. 46 C.T., el que expresamente lo menciona en caso de las violaciones que enuncia. De las leyes aportadas en los autos fluye que las partes demandantes tenían estabilidad laboral para invocar el reintegro a como lo hicieron en base a la Ley 293 Ley de Reformas a la Ley No. 210 y la Convención Colectiva que incorpora el Arto. 48 de la precitada Ley 293 en su cláusula 22, que también fue aportada a los autos. Estabilidad que estaría vigente durante el período de exclusividad a que remite el precitado Arto. 48 de la Ley 293. Puestas así las cosas existió violación a los derechos de los actores aquí recurrentes EINAR ARAUZ ECHEGOYEN, MAIRA ADILIA ECHEGOYEN MARTINEZ, JESSYKA PATRICIA GUEVARA MUÑOZ y WUELBER CASTILLO ORTIZ. No obstando la preocupación por tal estabilidad, que fue objeto de inclusión en instrumentos legales y el Convenio Colectivo; vigente. $\mathrm{Al}$ respecto de este último la Sala dijo en sentencia de las nueve y cincuenta y cinco minutos de la mañana del treinta de Abril del año dos mil tres ... "II.- De todo lo anterior colige la Sala, que conforme se consagra en Principio Fundamental III, de Libro Primero del C.T., que no es más que el principio conocido como de Norma Mínima viene a resultar que la Convención Colectiva, supera los 
mínimos de Derecho necesario establecidos en la Legislación Laboral. Y conforme el principio de norma más favorable que se manifiesta en el principio fundamental VIII del mismo Título Preliminar del C.T., no cabe discurrir que la Cláusula No. 21 Convenio Colectivo pactado entre ENITEL y sus trabajadores no supere los mínimos de Derecho necesario del C.T., en materia de estabilidad, máxime que este mismo Convenio contiene incorporado en su Cláusula 22, el Arto. 48 de la Ley No. 293 antes referida. Obviamente, la interpretación autèntica de tal artículo en la Ley NO. 436, viene a despejar la posible confusión que en materia de estabilidad laboral pudo haberse producido en la labor judicial". . . Es por ello, que independientemente del pago de prestaciones, no cabe tener como bien interpuesta la excepción de falta de acción pues la de reintegro fue intentada oportunamente y fue demostrado que se dieron las violaciones a tales instrumentos legales.

\section{POR TANTO}

Basándose en lo considerado, disposiciones legales citadas y Artos. 271, 272 y 347 C.T., los suscritos Magistrados,

\section{RESUELVEN}

I.- Ha lugar a la apelación intentada, revocándose la sentencia apelada. II.- Ha lugar a que LA EMPRESA NICARAGÜENSE DE TELECOMUNICACIONES Y CORREOS SOCIEDAD ANÓNIMA (ENITEL) por medio de quien le represente Reintegre a los señores EINAR ARÁUZ ECHEGOYEN, MAIRA ADILIA ECHEGOYEN MARTÍNEZ, JESSYKA PATRICIA GUEVARA MUÑOZ y WUELBER CASTILLO ORTIZ a su mismo puesto de trabajo en idénticas condiciones así como el pago de salarios caídos desde su despido hasta su efectivo reintegro. III.- No hay costas. Cópiese, Notifíquese y con testimonio concertado de lo resuelto vuelvan los autos al juzgado de origen.- HUMBERTO SOLÍS BARKER.---- A. GARCÍA GARCÍA.---- R. BÁRCENAS M.---- A. D. CÉSPEDES. SRIA. Es conforme con su original. Managua, diez de octubre del dos mil tres. 
